\title{
Development of Calcium Phosphate Cement for Rapid Crystallization to Apatite
}

\author{
Masayuki KON, Youji MIYAMOTO', Kenzo ASAOKA, \\ Kunio ISHIKAWA ${ }^{2}$ and Hae-Hyoung LEE \\ Department of Dental Engineering, ${ }^{1}$ First Department of Oral and \\ Maxillofacial Surgery, School of Dentistry, Tokushima University \\ 3-18-15 Kuramoto-cho, Tokushima 770-8504, Japan \\ ${ }^{2}$ Department of Biomaterials, Okayama University Dental School \\ 2-5-1 Shikata-cho, Okayama 700-8203, Japan
}

Received July 14, 1998/Accepted September 7, 1998

\begin{abstract}
The purpose of this study was to develop an $\alpha$-tricalcium phosphate ( $\alpha$-TCP) cement which transforms to hydroxyapatite (HAP) in a relatively short period. We used calcium and phosphate solutions as the liquid phase for the $\alpha$-TCP cement. The $\alpha$-TCP powder was first mixed with $\mathrm{CaCl}_{2}$ solution, and then mixed with $\mathrm{NaH}_{2} \mathrm{PO}_{4}$ or $\mathrm{Na}_{2} \mathrm{HPO}_{4}$ solution for a total powder/liquid ratio of 1.8. The setting time became shorter with the increase in the concentration of calcium and phosphate solutions, reaching $5 \mathrm{~min}$, whereas the setting time was longer than $30 \mathrm{~min}$ when distilled water was used as the liquid phase. X-ray diffraction analysis revealed that the cement was mostly transformed to HAP within $24 \mathrm{~h}$ when kept in an incubator. We concluded that $\alpha$-TCP should be mixed with calcium and phosphate solutions since this results in a moderate setting time and fast transformation to HAP even if the method of mixing becomes a little complex.
\end{abstract}

Key words: Calcium phosphate cement, Tricalcium phosphate, Hydroxyapatite

\section{INTRODUCTION}

Cement consisting of calcium phosphates is known to have an excellent tissue response. To give a typical example, cement $\mathrm{t}^{1-4)}$ powders consisting of tetracalcium phosphate (TTCP) and dicalcium phosphate (DCPA or DCPD) are hardened by mixing with water. Crystal phases in the set cement finally change to hydroxyapatite (HAP: $\left.\mathrm{Ca}_{10}\left(\mathrm{PO}_{4}\right)_{6}(\mathrm{OH})_{2}\right)$. HAP materials are known to bond with bone directly and thus can be used as bone-replacing materials ${ }^{5,6)}$. On the other hand, $\alpha$-tricalcium phosphate $\left(\alpha\right.$-TCP: $\left.\alpha-\mathrm{Ca}_{3}\left(\mathrm{PO}_{4}\right)_{2}\right)$ also sets to form calcium deficient HAP when mixed with water ${ }^{7)}$, and thus is used in dental clinics as a root sealer. The medical applications of $\alpha$-TCP cement have been investigated in terms of bioactivity and biocompatibility $^{8-11}$. The $\alpha$-TCP phase in the $\alpha$-TCP cement system takes a long time -several days-for the transformation to HAP. Therefore, $\alpha$-TCP abundantly exists in the set cement for a long time. This phenomenum has an adverse influence upon biocompatibility, because the $\alpha$-TCP phase of the set cement has high solubility. The solubility of $\alpha$-TCP is much higher than those of HAP and $\beta$-tricalcium phosphate $(\beta$-TCP), and thus it has not been thought suitable for use as a biomaterial. 
Moreover, the $\mathrm{pH}$ of the set cement surface increases as $\alpha$-TCP dissolves in the set cement $^{7)}$. This increase of $\mathrm{pH}$ in the $\alpha$-TCP cement results in the presence of inflammatory cells in the surrounding set cement until several weeks after implanta$\operatorname{tion}^{8,9,11,12)}$. However, $\alpha$-TCP has been reevaluated recently, and the use of an $\alpha$-TCPHAP mixture and a functionally gradient $\alpha$-TCP-HAP ceramic have become topics of interes $\mathrm{t}^{8,9,13,14)}$. It is $\mathrm{r}$ eported that composite materials composed of $\alpha$-TCP-HAP have better biocompatibility and bioactivity than HAP alone ${ }^{14,15)}$. These reports suggest that a small quantity of $\alpha$-TCP in composite calcium phosphate ceramics is better than a large quantity or no $\alpha$-TCP at all. Although the detailed mechanism of $\alpha$ TCP bioactivity has not yet been clarified, it seems reasonable that bone formation requires original materials, that is, calcium and phosphate. Thus a small quantity of remaining $\alpha$-TCP in the set cement may be effective, though a large quantity poses problems.

The aim of this study, therefore, was to develop a calcium phosphate ( $\alpha$-TCP) cement which transformed to HAP in a relatively short period. We used calcium chloride and sodium hydrogen phosphate solutions as the liquid phase, although the mixing liquid of $\alpha$-TCP cement is usually water. These solutions were selected because the mixture of calcium chloride and potassium hydrogen phosphate solutions precipitated needle-like HAP crystals with a large aspect ratio ${ }^{16)}$. However, the sodium hydrogen phosphate solution was introduced as a substitute for the potassium hydrogen phosphate solution because of its biocompatibility. We examined the rate of transformation to HAP and the properties of set $\alpha$-TCP cement mixed using various solutions, and found that this system was affected by the method used and the concentration of the solution employed.

\section{MATERIALS AND METHODS}

\section{Preparation of the specimens}

$\alpha$-TCP, the powder phase of cement used in this study, was prepared from a mixed powder consisting of calcium carbonate $\left(\mathrm{CaCO}_{3}\right)$ and dicalcium phosphate dihydrate (DCPD: $\mathrm{CaHPO}_{4} \cdot 2 \mathrm{H}_{2} \mathrm{O}$ ). The mixture, with a $\mathrm{Ca} / \mathrm{P}$ molar ratio of 1.5 , was fired at $1400^{\circ} \mathrm{C}$ for 5 hours. After heat treatment, x-ray diffraction of the resultant $\alpha$-TCP revealed no other crystal. The $\alpha$-TCP was crushed to a fine powder in an alumina ceramic cell by a ball mill (P-7 Planetary Micro Pulverizer, Fritsch Co., Idar Oberstein, Germany). The average particle size of the $\alpha$-TCP powder measured by a sedimentation method based on Stokes' law with the use of an automatic centrifugal particle analyzer (CAPA300, Horiba, Kyoto, Japan) was $2 \mu \mathrm{m}$. Liquid phases for mixing the $\alpha$-TCP powder were calcium chloride $\left(\mathrm{CaCl}_{2}\right)$ and sodium phosphate (either $\mathrm{NaH}_{2} \mathrm{PO}_{4} \cdot 2 \mathrm{H}_{2} \mathrm{O}$ or $\mathrm{Na}_{2} \mathrm{HPO}_{4} \cdot 12 \mathrm{H}_{2} \mathrm{O}$ ) solutions. Various concentrations of calcium and phosphate soluticns were prepared to investigate the crystal phase and properties of the set cement. To combine the powder and liquid phases, the powder phase was first mixed with $\mathrm{CaCl}_{2}$ solution, and then mixed with the same volume of one of the phosphate solutions $\left(\mathrm{NaH}_{2} \mathrm{PO}_{4} \cdot 2 \mathrm{H}_{2} \mathrm{O}\right.$ or $\left.\mathrm{Na}_{2} \mathrm{HPO}_{4} \cdot 12 \mathrm{H}_{2} \mathrm{O}\right)$ as for calcium solution at 
a total liquid ratio (powder/liquid) of 1.8. The total time for mixing of cement was 1.0 minute. Utensils used for the mixing consisted of a plate of glass and a spatula of stainless steel for dental zinc phosphate cement. After mixing, the cement paste was placed in a plastic mold, and the mold was kept in an incubator at a temperature of $37^{\circ} \mathrm{C}$ and relative humidity of approximately $100 \%$.

\section{Analysis of specimens}

The crystal phases in set cement were analyzed with a powder x-ray diffractometer system (XRD; ADG-301, Toshiba Co., Tokyo, Japan). The XRD conditions were Ni monochromatized $\operatorname{CuK} \alpha$ radiation $(\lambda=0.1540 \mathrm{~nm})$ generated at $30 \mathrm{kV}$ and $12 \mathrm{~mA}$. The specimen for XRD analysis was prepared by crushing the set cement or paste with an agate mortar. A scanning electron microscope (SEM; S-700, Hitachi Co., Tokyo, Japan) was used to observe the microstructure of set cement. For SEM observation, the set cement was sputtered with gold. The setting time of cement specimens was measured using a Vicat-needle, according to the method of Japanese Industrial Standard JIS T6602 (Correspondence: ISO 1566) for dental zinc phosphate cement. Measurement was carried out at room temperature (approximately $20^{\circ} \mathrm{C}$ ).

\section{Strength}

The strength of set cement was evaluated by the wet diametral tensile strength (DTS) test. The cement paste was filled into a split mold (6 mm diameter $\times 3 \mathrm{~mm}$ height), and the mold with the paste was stored in the incubator for 24 hours. After storage, the wet DTS of 10 pieces for each concentration of mixing liquids was estimated using a Universal Testing Machine (AGS-500A Autograph, Shimadzu Corp., Kyoto, Japan), with a cross-head speed of $1.0 \mathrm{~mm} \cdot \mathrm{min}^{-1}$.

\section{RESULTS}

Fig. 1 shows the XRD patterns for the crystal phase in set cement when the $\alpha$-TCP powder used in this study was mixed with distilled water. The crystal phase of the powder before mixing was completely $\alpha$-TCP. The crystal phase of set cement was observed to be almost all $\alpha$-TCP by XRD at 7 days after mixing. After 14 days, the $\alpha$-TCP in the crystal phase of set cement was decreased by approximately one-half. HAP crystals eventually crystallized in set cement. The crystal phase for a commercial root sealer (Type 1, Sankin Industry, Tochigi, Japan) consisting of $\alpha$-TCP powder was measured by XRD. After 7 days in an incubator following setting, the crystal phase of $\alpha$-TCP was also the same as the powder phase. Fig. 2 shows XRD patterns of the changes of the crystal phase in set cement using $1.0 \mathrm{~mol} / \mathrm{L} \mathrm{CaCl}_{2}$ solution and $0.6 \mathrm{~mol} / \mathrm{L} \mathrm{NaH} \mathrm{PO}_{4}$ solution as mixing liquids for 24 hours after mixing. One hour after mixing, HAP crystals were slightly crystallized in the set cement. Six hours after mixing, the HAP content in set cement was increased, and $\alpha$-TCP content was decreased. Compared with distilled water as the mixing liquid, the crystal phase in set cement was almost all transformed from $\alpha$-TCP to HAP after 24 hours by the 


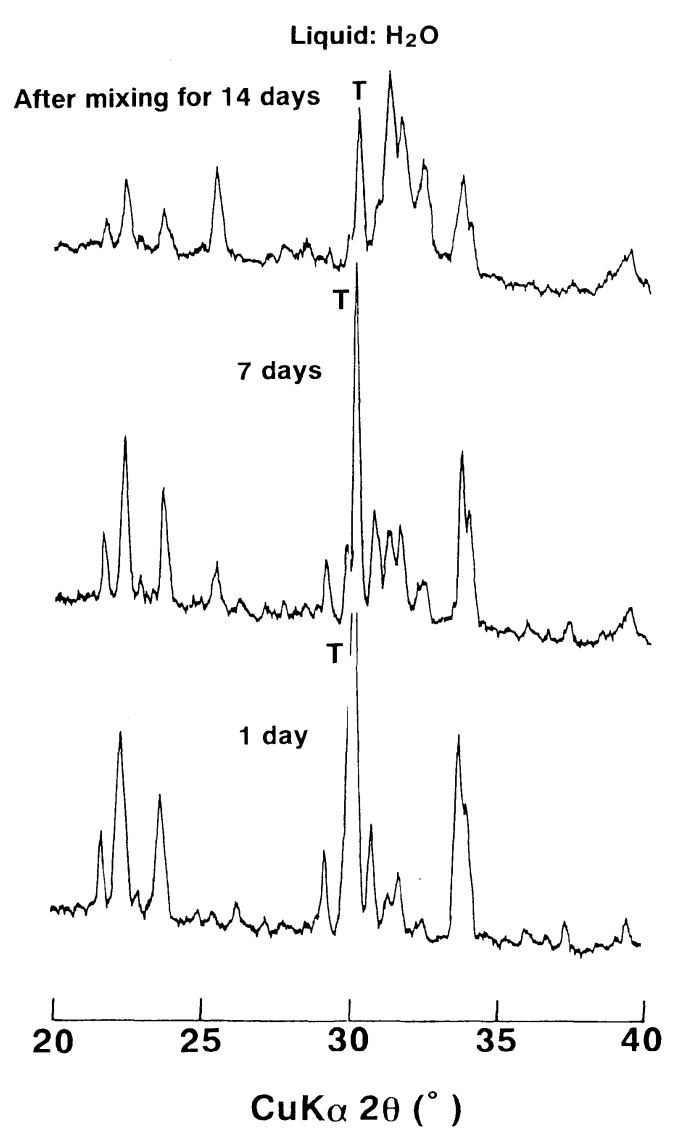

Fig. 1 Powder X-ray diffraction patterns of set cement at 1,7 , and 14 days after mixing, when $\alpha$-tricalcium phosphate powder produced in this study was mixed with distilled water. After mixing, the paste was kept in an incubator at $37^{\circ} \mathrm{C}$ and relative humidity $100 \%$. ( $\mathrm{T}=$ the maximal peak of $\alpha$ tricalcium phosphate).

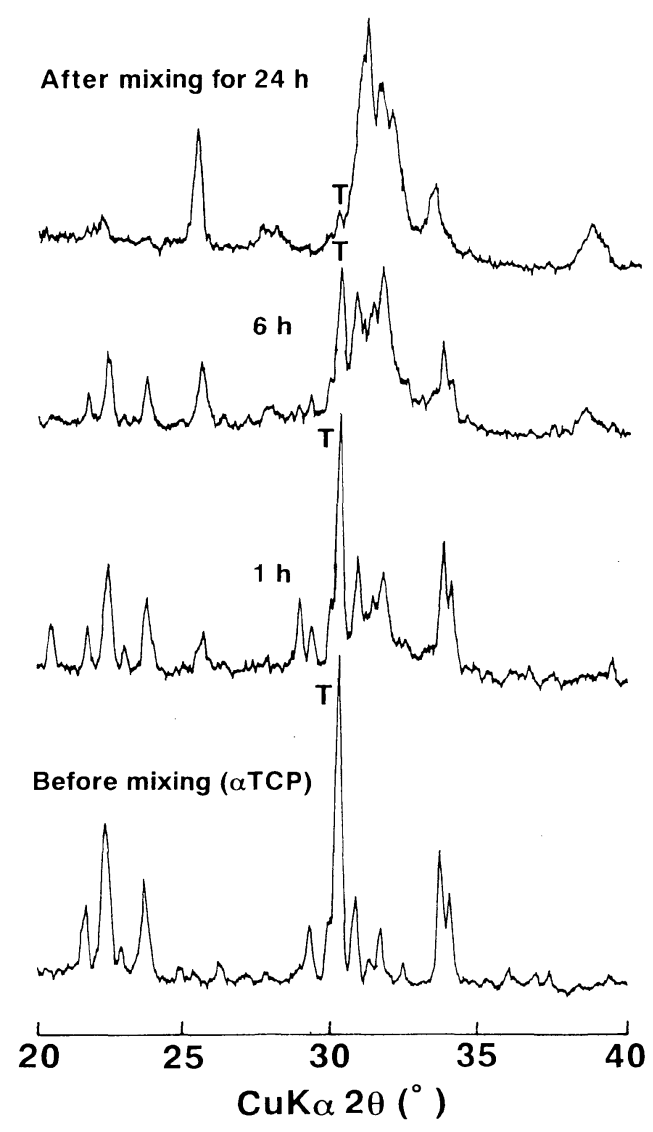

Fig. 2 Powder X-ray diffraction patterns of the changes of the crystal phase in set cement using $1.0 \mathrm{~mol} / \mathrm{L} \cdot \mathrm{CaCl}_{2}$ and $0.6 \mathrm{~mol} / \mathrm{L} \mathrm{NaH} \mathrm{PO}_{4}$ solutions as mixing liquids, for 24 hours. After mixing, the paste was kept in an incubator at $37^{\circ} \mathrm{C}$ and relative humidity $100 \%$. ( $\mathrm{T}=$ the maximal peak of $\alpha$-tricalcium phosphate; $\alpha \mathrm{TCP}=\alpha$ tricalcium phosphate).

use of the calcium and phosphate solutions as mixing liquids. On the other hand, the crystal phase in set cement using $0.6 \mathrm{~mol} / \mathrm{L} \mathrm{Na}_{2} \mathrm{HPO}_{4}$ solution as a substitute for 0.6 $\mathrm{mol} / \mathrm{L} \quad \mathrm{NaH}_{2} \mathrm{PO}_{4}$ solution was also transformed after 24 hours. However, the crystallity of HAP in the set cements using $\mathrm{NaH}_{2} \mathrm{PO}_{4}$ solution was slightly higher than that with $\mathrm{Na}_{2} \mathrm{HPO}_{4}$ solution. These results suggested that the mixing liquids used in this study were markedly more effective than distilled water for mixing. However, the rate of transformation to HAP in set cement decreased with increased solution concentration. In the case of set cement mixed simultaneously with calcium chloride 
and sodium hydrogen phosphate, DCPD was rapidly produced in the crystal phase of set cement. The DCPD in set cement existed for a long time; in addition, the crystallizing rate of HAP was decreased by the existence of DCPD.

When only calcium or phosphate solution was used in the set cement, rapidcrystallization to HAP did not occur. The use of only $\mathrm{NaH}_{2} \mathrm{PO}_{4}$ or $\mathrm{Na}_{2} \mathrm{HPO}_{4}$ phosphate solution, in particular, decreased the rate of transformation to HAP. These transformation rates were similar to that obtained with distilled water. However, the use of $\mathrm{CaCl}_{2}$ solution was more effective than the distilled water and phosphate solutions. The XRD patterns of set cement mixed with $\mathrm{CaCl}_{2}$ solution for several elapsed times (1, 7, and 14 days) are summarized in Fig. 3 . Approximately $30 \%$ of HAP was crystallized into $\alpha$-TCP at 1 day (24 hours) after mixing, though the transformation rate was less than that obtained when using the calcium and phosphate solutions together. Seven days after mixing, the remaining $\alpha$-TCP in set cement was almost all transformed to HAP.

SEM micrograph of the inside of the set cement made using $\mathrm{CaCl}_{2}(1.0 \mathrm{~mol} / \mathrm{L})$ and $\mathrm{NaH}_{2} \mathrm{PO}_{4}(0.6 \mathrm{~mol} / \mathrm{L})$ obtained at 24 hours after mixing is shown in Fig. 4 . It was

Liquid: $\mathrm{CaCl}_{2}$

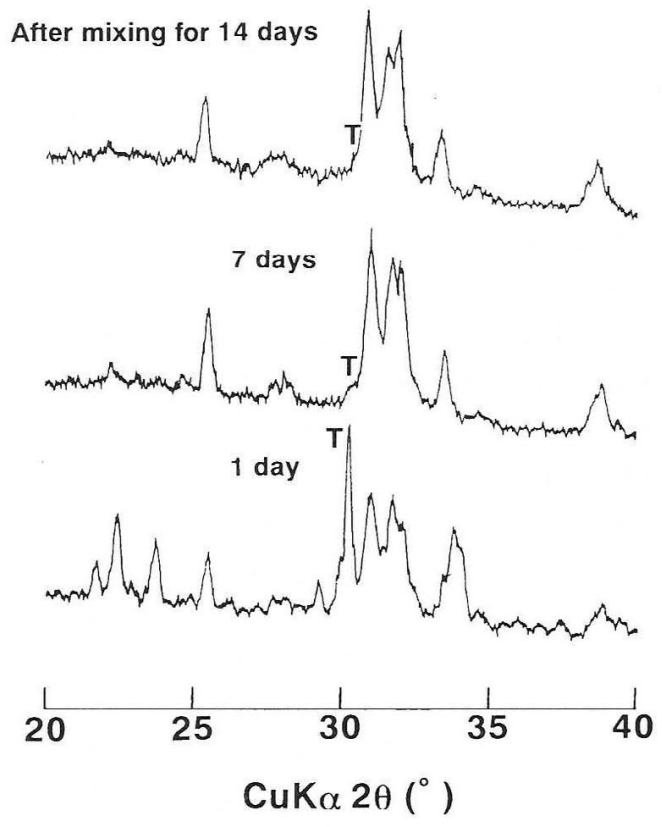

Fig. 3 Powder X-ray diffraction patterns of set cement mixed with $1.0 \mathrm{~mol} / \mathrm{L}$ $\mathrm{CaCl}_{2}$ solution for several elapsed times $(1,7$, and 14 days). After mixing, the paste was kept in an incubator at $37^{\circ} \mathrm{C}$ and relative humidity $100 \%$. ( $\mathrm{T}=$ the maximal peak of $\alpha$ tricalcium phosphate).

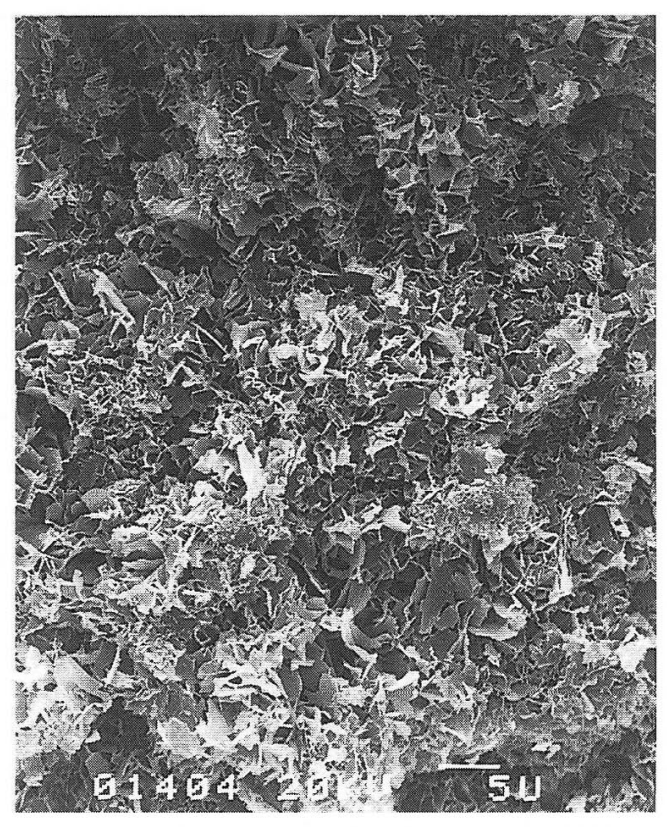

Fig. 4 Inside microstructure of set cement (after $24 \mathrm{~h}$ ) mixed with $1.0 \mathrm{~mol} / \mathrm{L}$ $\mathrm{CaCl}_{2}$ and $0.6 \mathrm{~mol} / \mathrm{L} \mathrm{Na}_{2} \mathrm{HPO}_{4}$ solutions, observed by scanning electron microscopy. (Scale bar $=5 \mu \mathrm{m}$ ). 


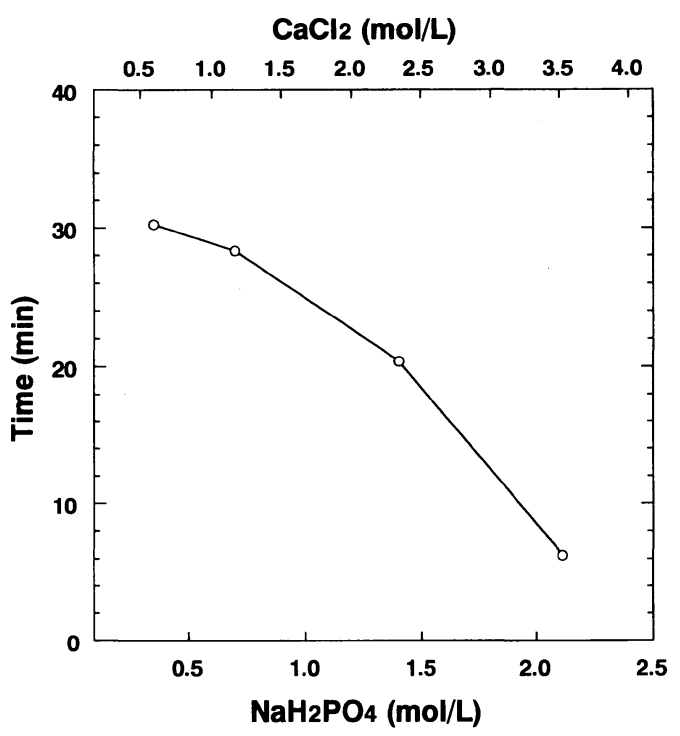

Fig. 5 Relation between setting time of cement pastes and concentration of mixing liquids. The calcium and phosphate solutions for mixing liquids were used with the $\mathrm{Ca} / \mathrm{P}$ ratio of 1.67 , at all times.

confirmed by SEM observation that plate-like crystals were crystallized in the set cement. Inside the set cement a porous structure was formed by the entangling of plate-like crystals. The plate-like crystals in set cement were also crystallized with using $0.6 \mathrm{~mol} / \mathrm{L} \mathrm{Na}_{2} \mathrm{HPO}_{4}$ solution as a substitute for $0.6 \mathrm{~mol} / \mathrm{L} \mathrm{NaH} \mathrm{PO}_{4}$ solution.

The setting time of cement measured by the Vicat-needle method became shorter with the increase in the $\mathrm{CaCl}_{2}$ and $\mathrm{NaH}_{2} \mathrm{PO}_{4}$ concentrations, reaching 5 min when the concentration of the $\mathrm{NaH}_{2} \mathrm{PO}_{4}$ was $2.2 \mathrm{~mol} / \mathrm{L}$, as shown in Fig. 5 . The setting time was longer than 30 min when distilled water was used as the liquid phase. In the case of cement paste using $\mathrm{Na}_{2} \mathrm{HPO}_{4}$ solution as a substitute for $\mathrm{NaH}_{2} \mathrm{PO}_{4}$ solution, the setting time was also delayed with the decrease in the concentrations of mixing liquids. However, the setting time using $\mathrm{Na}_{2} \mathrm{HPO}_{4}$ solution was slightly longer than that with $\mathrm{NaH}_{2} \mathrm{PO}_{4}$ solution. Fig. 6 shows the relation between the $\mathrm{Ca} / \mathrm{P}$ ratio of the two mixing liquids and the setting time of cement pastes. The influence of the $\mathrm{Ca} / \mathrm{P}$ ratio on setting time was measured in the range from 0.5 to 5.0 of $\mathrm{Ca} / \mathrm{P}$ ratio by using 1.4 $\mathrm{mol} / \mathrm{L} \mathrm{NaH}_{2} \mathrm{PO}_{4}$ solution and various $\mathrm{CaCl}_{2}$ solutions. The setting time was delayed with the increase of the $\mathrm{Ca} / \mathrm{P}$ ratio in the mixing liquids. In the case of a $\mathrm{Ca} / \mathrm{P}$ ratio of 1.67 , the setting time of the cement was $21 \mathrm{~min}$.

The relation between DTS of set cements and concentration of mixing liquids is shown in Fig. 7. The calcium and phosphate solutions for mixing liquids were used with the $\mathrm{Ca} / \mathrm{P}$ ratio of 1.67 , at all times. The DTS of the set cement after 24 hours 


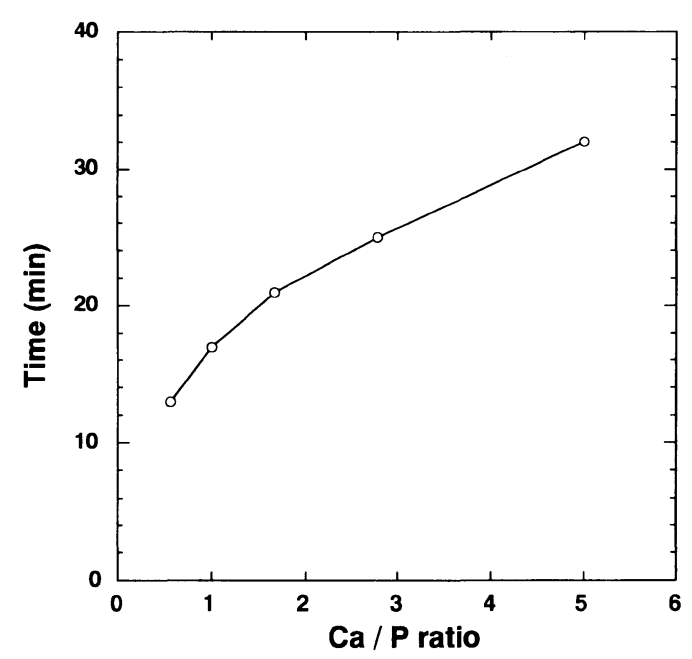

Fig. 6 Relation between setting time of cement pastes and $\mathrm{Ca} / \mathrm{P}$ ratio of the two mixing liquids. The mixing liquids for various $\mathrm{Ca} / \mathrm{P}$ ratio were used with $1.4 \mathrm{~mol} / \mathrm{L} \mathrm{NaH}_{2} \mathrm{PO}_{4}$ solution and various $\mathrm{CaCl}_{2}$ solutions.

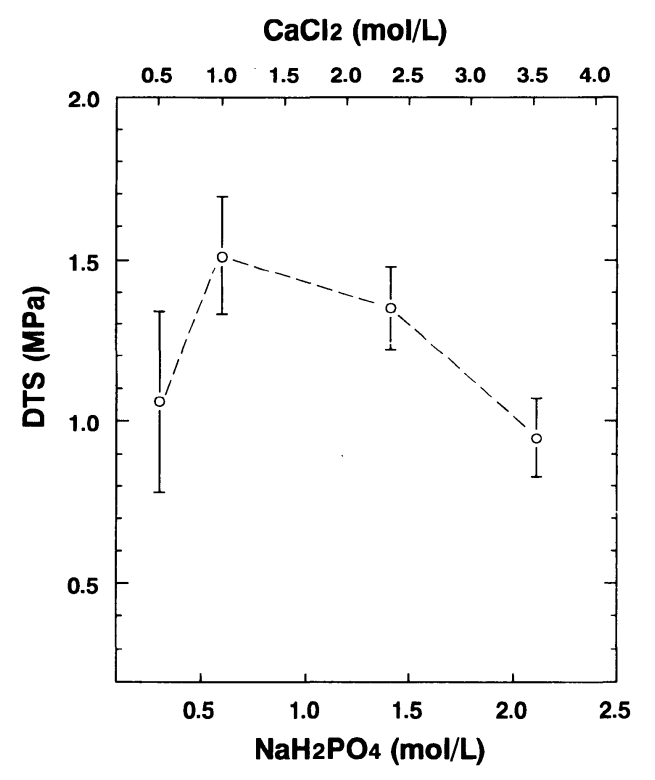

Fig. 7 Relation between diametral tensile strength (DTS) of set cements and concentration of mixing liquids. After setting, the set cement was kept in an incubator at $37^{\circ} \mathrm{C}$ and relative humidity $100 \%$.

was $1.5 \pm 0.2 \mathrm{MPa}$ when $\alpha$-TCP was mixed with $\mathrm{CaCl}_{2}(1.0 \mathrm{~mol} / \mathrm{L})$ solution followed by $\mathrm{NaH}_{2} \mathrm{PO}_{4}(0.6 \mathrm{~mol} / \mathrm{L})$ solution. This mixture gave the maximum value of DTS. The bulk density of this set cement was $1.37 \pm 0.03 \mathrm{~g} / \mathrm{cm}^{3}$ after storage in a desiccator at $80^{\circ} \mathrm{C}$ for 5 hours.

\section{DISCUSSION}

HAP powders prepared by wet synthesis are known to form needle-like crystal, platelike crystal or grain-like crystal. The $\alpha$-TCP cement used in this study crystallized plate-like crystals of HAP, as confirmed by SEM observation. Ohgaki et al. reported that needle-like crystals of HAP were obtained by dropping $\mathrm{CaCl}_{2}$ and dipotassium hydrogen phosphate $\left(\mathrm{K}_{2} \mathrm{HPO}_{4}\right)$ solutions into $100^{\circ} \mathrm{C}$ water ${ }^{16)}$. They explained that the needle-like crystal was produced from the first precipitation of DCPD. Moreover, they demonstrated that the aspect ratio of the needle-like crystal decreased with an increase of the $\mathrm{Ca} / \mathrm{P}$ ratio between calcium acetate $\left(\mathrm{Ca}\left(\mathrm{CH}_{3} \mathrm{COO}\right)_{2}\right)$ and $\mathrm{K}_{2} \mathrm{HPO}_{4}$ solutions ${ }^{17)}$. These results may suggest that a region of low $\mathrm{pH}$ promotes the precipitation of needle-like HAP crystals. The typical calcium phosphate cement consisting of TTCP and DCPA (or DCPD) also forms the needle-like crystals of HAP, and is hardened by entanglement in the needle-like crystals $^{2,3,18,19}$. Therefore, it seems that DCPD 
participates before the formation of the needle-like crystal of HAP. The cement in this study was also able to crystallize DCPD, depending on the conditions of the mixing liquids and the method employed. However, the crystallization of DCPD in set cement decreases the transformation rate of HAP because the DCPD exists for a long time. From the results of this study, the mixing conditions for rapid-crystallization to HAP caused the plate-like crystals of HAP to be formed (Fig. 4). The presence of plate-like crystals in the set cement suggested that $\alpha$-TCP was transformed to HAP via an octacalcium phosphate $\left(\mathrm{OCP}: \mathrm{Ca}_{8} \mathrm{H}_{2}\left(\mathrm{PO}_{4}\right)_{6} \cdot 5 \mathrm{H}_{2} \mathrm{O}\right)$ phase because the plate-like crystal originates from a crystal form of OCP. Graham and Brown reported that $\alpha$-TCP is transformed to HAP through precipitation of OCP under the environmental conditions of a basic region ${ }^{20)}$. Moreover, Fulmer et al. demonstrated that calcium deficient HAP in a mixture consisting of TTCP and monocalcium phosphate monohydrate (MCPM) was rapidly precipitated by use of $\mathrm{Ca}(\mathrm{OH})_{2}{ }^{21}$. The $\mathrm{pH}$ of this cement paste will become basic when $\alpha$-TCP powder is first mixed with calcium solution. Therefore, a crystalline nucleus of OCP may be produced by the first mixing with calcium solution. However, XRD analysis in this study was not able to detect a peak $\left(2 \theta=4.5^{\circ}\right)$ of OCP in set cement. After the first mixing, the cement paste rich in calcium will be offset by the second mixing with phosphate solution. We guess that the rapid crystallization to HAP was due to the precipitation of OCP.

The DTS of set cement was lower than those of the other calcium phosphate cements ${ }^{19,22}$. The reason for this low strength may have been the bulk density of platelike crystals being lower than that of needle-like crystals. The calcium phosphate cements that crystallize HAP needle-like crystals have high streng $\operatorname{th}^{2,19)}$ compared with the cement in this study. The densities of HAP and $\alpha-$ TCP are $3.16 \mathrm{~g} / \mathrm{cm}^{3}$ and 2.86 $\mathrm{g} / \mathrm{cm}^{3}$, respectively. On the assumption that the $\alpha$-TCP of powder phase completely transformed to HAP, the porosity for set cement of the maximum DTS value is approximately $57 \%$, calculated from the bulk density $\left(1.37 \mathrm{~g} / \mathrm{cm}^{3}\right)$. The porosity of calcium phosphate cement consisting of TTCP and DCPA ranged from $40 \%$ to $45 \%$ using powder/liquid $(\mathrm{P} / \mathrm{L})$ ratios from 3.0 to $6.0^{19)}$. Therefore, it is possible that the DTS in this study was increased by the increased $\mathrm{P} / \mathrm{L}$ ratio. The strength of the set cement needs to be investigated before clinical application. However, the use of this $\alpha$-TCP cement system may be in conflict with the need for strength and rapidcrystallization to HAF.

Generally, the raw materials used for the precipitation of HAP are tetracalcium phosphate (TTCP), ostacalcium phosphate (OCP), dicalcium phosphate dihydrate (DCPD), dicalcium phosphate (DCPA), monocalcium phosphate monohydrate (MCPM), $\alpha$-TCP and $\beta$-TCP 22 . These calcium phosphates are not stable compounds under environmental conditions around neutral $\mathrm{pH}$, compared with HAP. When these compounds of calcium phosphate in cement dissolve in vivo, an increase or decrease of $\mathrm{pH}$ occurs on the cement surface because of its dissolution ${ }^{22,23)}$. One of the important factors for biomaterials is that of biocompatibility. The biocompatibility of a material is governed by the character of the surface layer. The surface of HAP shows excellent biocompatibility because a small quantity of HAP dissolution causes 
almost no change in $\mathrm{pH}$ at the HAP surface. The $\mathrm{pH}$ of biomaterial surfaces should be neutral. Therefore, it is desirable that the crystal phase in cement consisting of calcium phosphate transforms to HAP as fast as possible. We demonstrated that the powder phase ( $\alpha$-TCP) of set cement in this study was transformed to HAP within 24 hours after mixing when kept in an incubator. Though the biocompatibility and bioactivity in vivo of the cement have not yet been clarified, the results of this study suggest that the biocompatibility of the cement will be better than that of the conventional $\alpha$-TCP cement because of its rapid-crystallization to HAP. $\alpha$-TCP has been known to increase $\mathrm{pH}$ when it dissolves in water. The $\alpha$-TCP powder prepared in this study also showed markedly increased $\mathrm{pH}$. The $\mathrm{pH}$ of the $\mathrm{NaH}_{2} \mathrm{PO}_{4}$ solution used for the liquid phase in this study was approximately 4.5 in $0.6 \mathrm{~mol} / \mathrm{L}$ solution. Therefore, it seems that the low $\mathrm{pH}$ of $\mathrm{NaH}_{2} \mathrm{PO}_{4}$ solution will offset the increase of $\mathrm{pH}$ in the $\alpha$-TCP cement. If this hypothesis is correct, the $\mathrm{pH}$ of cement paste may be nearly neutral. Moreover, this cement could be a better biocompatible material than the conventional $\alpha$-TCP cement.

\section{CONCLUSION}

The rapid crystallization to HAP of calcium phosphate ( $\alpha$-TCP) cement was investigated by using various mixing liquids. The results suggested that the crystal phase in set cement could be changed from $\alpha$-TCP to HAP within 24 hours by the use of two mixing liquids consisting of calcium chloride $(1.0 \mathrm{~mol} / \mathrm{L})$ and sodium hydrogen phosphate $(0.6 \mathrm{~mol} / \mathrm{L})$ solutions. It seems that $\alpha$-TCP cement improved by using these mixing liquids is more effective in terms of biocompatibility than conventional $\alpha$-TCP cements.

\section{ACKNOWLEDGMENTS}

This study was supported by a Grant-in-Aid for Scientific Research from the Ministry of Education, Science, Sports and Culture, Japan (C) 09671993.

\section{REFERENCES}

1) Brown, W. and Chow, L. C.: Combinations of sparingly soluble calcium phosphates in slurries and paste as mineralizers and cement, US Patent No.4, 612, $053,1986$.

2) Brown, W. and Chow, L. C.: A new calcium phosphate cements, water setting cement, In: Brown PW ed. Cement Research Progress, Westerville, OH: American Ceramic Society, 1986, pp.351-379.

3) Ishikawa, K., Takagi, S., Chow, L. C. and Ishikawa, Y.: Properties and mechanisms of fast-setting calcium phosphate cements, J Mater Sci: Mater Med 6(9) : 528-533, 1995.

4) Doi, Y., Takezawa, Y., Shibata, S., Wakamatsu, N., Kamemizu, H., Goto, T., Iijima, M., Moriwaki, Y., Uno, K., Kubo, F. and Haeuchi, Y.: Self-setting apatite cement, $J J$ Dent Mater 6(1):53-58, 1987. (in Japanese)

5) Ducheyne, P. and De Groot, K.: In vivo surface activity of a hydroxyapatite alveolar bone substitute, $J$ Biomed Mater Res 15 : 441-445, 1981.

6) Aoki H.: Medical applications of hydroxyapatite, Ishiyaku Euro America, St. Louis, 
1994, pp.13-74.

7) Monma, H. and Kanazawa, T.: The hydration of $\alpha$-tricalcium phosphate, $J$ Ceram Soc Jpn (Yogyo-kyoukai-shi) 84(4): 209-213, 1976.

8) Nagase, M., Cherı, R. B., Asada, Y. and Nakajima, T.: Radiographic and microscopic evaluation of subperiosteally implanted blocks of hydrated and hardened $\alpha$-tricalcium phosphate in rabbits, $J$ Oral Maxillofac Surg $47: 582-586,1989$.

9) Nagase, M., Cher, R. B., Araya, Y. and Nakajima, T.: Evaluation of a bone substitute prepared from a-tricalcium phosphate and an acid polysaccharide solution, $J$ Oral Maxillofac Surg 49:1305-1309, 1991.

10) Kosino, T., Takahashi, A. and Kubota, W.: Bioactive cement, The Bone 6(4) : 43-47, 1992. (in Japanese)

11) Sato, J., Yasumoto, S. and Seto, K.: Development and clinical application of self-setting apatite cement, Liental Diamond $8: 112-117,1992$. (in Japanese)

12) Komoriya, T., Arai, H., Koda, K. and Iwaku, M.: Study on $\alpha$ TCP for direct pulp capping, Japan J Conserv Dent 29(2): 774-780, 1986. (in Japanese)

13) Kon, M., Ishikawa, K., Miyamoto, Y. and Asaoka, K.: Development of calcium phosphate based functional gradient bioceramics, Biomaterials 16(9) : 709-714, 1995.

14) Harada, Y.: Experimental studies of healing process on compound blocks of hydroxyapatite particles and tricalcium phosphate powder implantation in rabbit mandible, Journal of T'okyo Dental College Society 89 : 263-297, 1989.

15) Fukao, H., Miyamoto, Y., Sawada, M., Nagayama, M., Kon, M., Ishikawa, K. and Asaoka, K.: In vivo reactions of functionally gradient ceramic calcium phosphate, The 3rd World Congress for Oral Implantology, Program \& Abstracts, Yokohama Japan, 1994, p.315.

16) Ohgaki, M., Ozavsa, M. and Suzuki, S.: Preparation of needle-like hydroxyapatite, Proceeding of Annual Meeting of Ceramic Society of Japan, 1995, p.119. (in Japanese)

17) Suzuki, S., Ohgaki, M., Ichiyanaki, M. and Ozawa, M.: Preparation of needle-like hydroxyapatite, e' Mater Sci Lett $17: 381-383,1998$.

18) Brown, P.W., Hocker, N. and Hoyle, S.: Variations in solution chemistry during the low-temperature formation of hydroxyapatite, J Am Ceram Soc 74(8) : 1848-1854, 1991.

19) Ishikawa, K. and Asaoka, K.: Estimation of ideal mechanical strength and critical porosity of calcium phosphate cement, $J$ Biomed Mater Res $29:$ 1537-1543, 1995.

20) Graham, S. and Brown, P. W.: The low temperature formation of octacalcium phosphate, J Crysal Growth 132 : 215-225, 1993.

21) Fulmer, M. T., Martin, R. I. and Brown, P.W.: Formation of calcium deficient hydroxyapatite at near-physiological temperature, J Mater Sci: Mater Med 3:299-305, 1992.

22) Monma, H.: Material sciences of calcium phosphate cement, $J$ Jpn Sci for Biomaterials 15(1) : 24-30, 1997. (in Japanese)

23) Driessens, F. C. M., Boltong, M. G., Bermudez, O., Planell, J. A., Ginebra, M. P. and Fernandez, E.: Effective formulations for the preparation of calcium phosphate bone cements, J Mater S'ci: Mater Med 5 : 164-170, 1994. 